\title{
Constant-Resistance, Rigid, and Flexible Coupling Support Technology for Soft Rock Entrances in Deep Coal Mines: A Case Study in China
}

\author{
Yong Zhang, ${ }^{1,2}$ Chengwei Zhao, ${ }^{1,2}$ Ming Jiang,, Jiaxuan Zhang, ${ }^{1,2}$ Chen Chen,,2 \\ Xiaoyu Zheng, ${ }^{1,2}$ Xiaoming Sun (iD), ${ }^{1,2}$ and Huichen $\mathrm{Xu}$ (D) $^{3}$ \\ ${ }^{1}$ State Key Laboratory for Geomechanics and Deep Underground Engineering, China University of Mining and Technology, \\ Beijing 100083, China \\ ${ }^{2}$ School of Mechanics \& Civil Engineering, China University of Mining and Technology, Beijing 100083, China \\ ${ }^{3}$ College of Mechanical and Architectural Engineering, Taishan University, Taian, Shandong 271000, China
}

Correspondence should be addressed to Xiaoming Sun; sunxiaoming@cumtb.edu.cn and Huichen Xu; xhccumtb@163.com

Received 19 April 2020; Revised 27 August 2020; Accepted 22 September 2020; Published 7 October 2020

Academic Editor: Antonio Caggiano

Copyright $\odot 2020$ Yong Zhang et al. This is an open access article distributed under the Creative Commons Attribution License, which permits unrestricted use, distribution, and reproduction in any medium, provided the original work is properly cited.

The stability control of a soft rock roadway is a crucial problem for sustainable utilization of limited coal resources in deep mining practices. To solve it, the soft rock types and failure mechanism of -890 entrance surrounding rock have been analyzed, taking Daqiang Coal Mine of China as an engineering example. The analysis shows that the damage to the surrounding rock was characterized by asymmetry, large deformation, severe damage, and extended durations. The surrounding rock can be divided into high-stress-jointed-strong expansion soft rock based on S-M scanning and mineral analysis. Numerical simulation is used to reproduce the failure process of the original supporting system and analyze the deformation of the surrounding rock, range of plastic zone, and distribution of the stress field. The failure mechanism is thus defined for a deep soft rock roadway. Combined with the above studies, the deformation mechanics of the surrounding rock is summarized as type $\mathrm{I}_{\mathrm{AB}} \mathrm{II}_{\mathrm{AB}} \mathrm{III}_{\mathrm{ABC}}$. The stability transformation mechanism of the surrounding rock is proposed, based on which the control principle of deformation stability of a surrounding rock is formed. According to the control principle, "high strength support controls the surrounding rock deformation. The large deformation of the flexible support system releases the accumulated energy to the surrounding rock, and long-term deformation of the surrounding rock is controlled by high strength truss support." Meanwhile, the constant-resistance, rigid, and flexible coupling (CRRFC) support system is proposed. The numerical analysis demonstrated that the CRRFC support system can effectively reinforce the shallow surrounding rock and improve the bearing capacity. Simultaneously, the development of the surrounding rock malignant plastic zone is effectively controlled. The application results show that the large deformation of the roadway can be effectively controlled by the CRRFC support system, which provides applications for similar engineering.

\section{Introduction}

Due to the depletion of shallow mining resources, the mining of coal in China has gradually entered the deep complex and difficult mining stage. Increased mining depth has resulted in increased complexity of the geomechanical environment of engineering rock masses. Given the deep, "three-high, and one-disturbance" complex geomechanical environment, the problem of stability control of the surrounding rock of roadway under complex geological conditions has become increasingly prominent $[1,2]$. As a typical type of roadways, with difficult stability control, a deep soft rock roadway with a large cross section is prone to large deformation and failure phenomena such as roof caving, shrinkage, and floor heave [3]. Therefore, it is of great significance for the safe production of coal to study the failure mechanism of deep soft rock entrance roadway and put forward scientific and advanced control technology.

Many scholars have carried out useful research on deformation and failure mechanisms and support technology 
of deep soft rock roadways and proposed various scientific control countermeasures for the stability of soft rock roadways [4-7]. To solve the problems of large deformation, extended durations, and a large degree of damage to deep soft rock roadway, Wang et al. invented a restrained concrete support system, which solved the problem of the field surrounding rock control $[8,9]$. Sun et al. pointed out that the engineering rock mass of deep soft rock roadways has entered the stage of large plastic deformation, and the main reason behind the failure of the surrounding rock roadway lies in the uncoupling between the supporting and surrounding rock. Accordingly, a nonlinear design method of anchor-mesh-cable coupling support is proposed [10]. Yang et al. proposed a combined support scheme with bolt + cable + mesh + shotcrete + shell to improve supporting strength [11]. L. P. S. points out that improving the prestress of the support system can effectively control the stability of jointed rock mass [12]. Yuan et al. focused on the complex geological conditions of surrounding rock of deep roadway in Huainan mining area and proposed the supporting technology and system of deep roadway surrounding rock, based on "stress recovery and improvement, surrounding rock reinforcement and consolidation repair, stress transfer and bearing circle expansion, and distribution combined support and technology" [13]. Sun et al. studied mechanical properties under static pull test conditions [14]. Niu et al. created the rigid-flexible coupling dynamic reinforcement technology based on the typical deep, extremely soft rock roadway [15]. According to the deformation and failure characteristics of soft rock roadway, Sun et al. proposed the coupling support mode of constant-resistance large deformation (CLRD) bolt + metal mesh + bottom angle anchor pipe + steel fiber reinforced concrete, which solved the stability problem of the soft rock roadway [16]. Kang et al. improved the existing anchor bolt support system to solve the stability control problem of the tailgate [17].

The studies mentioned above verify that the stability of a deeply buried soft rock roadway is extremely difficult to control. At the same time, they also highlight the solutions to problems including (1) support strength sufficiency to limit the initial deformation of surrounding rock; (2) high prestress that limits the development and expansion of fractures in the surrounding rock; (3) the control of the long-term rheology of roadway surrounding rock by a high-stiffness support system.

The geological conditions of Daqiang Coal Mine are complex, and the original support is difficult to meet the requirements of surrounding rock deformation. This study hopes to contribute to the academic literature supporting roadways with soft rock. An entrance roadway in Daqiang Coal Mine, a deep mine with soft rock in China, is taken as the engineering example. The soft rock type of the entrance roadway is confirmed by engineering investigation, $\mathrm{X}$-ray, and S-M scanning experiments. Based on the analysis of the mechanisms of surrounding rock deformation and the stability control transformation, CRRFC support technology is proposed. The reliability of the new technology has been verified by numerical analysis and on-site tests. The successful on-site tests indicate that the new support system is a good solution in supporting the roadways with soft rock.

\section{Engineering Geological Conditions}

2.1. Project Background. Daqiang Coal Mine is located in Shen Yang City, Liaoning Province, as shown in Figure 1. It is the deepest soft rock mine in the northeast region and the deepest soft rock mine from the Mesozoic in China. The design depths of the main shaft, auxiliary shaft, and air shaft of the coal mine are about $1000 \mathrm{~m}$. The faults in the well are relatively developed (as shown in Figure 1), and the tectonic stress is affected by local faults. The faults developed near the wellbore toward north-north-west, and the tectonic stress is nearly east-west compressional stress. The -890 entrance roadway is located in the Mesozoic Jurassic strata, the lithology of which is dominated by siltstone and sandy mudstone; the stratigraphic column is shown in Figure 2(a). The entrance roadway section is a straight wall semicircular arch with a net width of $5.46 \mathrm{~m}$, height of $4.15 \mathrm{~m}$, and wall height of $1.5 \mathrm{~m}$. The original support adopted an anchor bolt-net-spray support + pouring concrete. The support section design scheme is shown in Figure 3. The mining area was mainly a fault structure. The fold structure was not developed, and the faults in the mine are relatively welldeveloped. As shown in Figure 1, the developed faults near the shaft follow a north-northwest direction, and the tectonic stress is affected by local faults that are near the eastwest compression stress.

2.2. Soft Rock Type of Surrounding Rock. According to the mine geology report, the surrounding rock is relatively broken, and the bedding is relatively well-developed. Waterbased swelling, softening, and rock mass strength are relatively low, as shown in Figure 2(b). Through accurate field surveys, after the surrounding rock section is tunneled and formed, the horizontal interface is very obvious, with a small layer thickness and a large number of layers; at the same time, the development of vertical fissures is remarkable.

The results of SEM show that medium-grained sandstone has $30-50 \mu \mathrm{m}$ intergranular voids and interlayer cracks $2-3 \mu \mathrm{m}$. Mudstone has 3-5 $\mu \mathrm{m}$ intergranular voids and interlayer cracks $2-3 \mu \mathrm{m}$, with good connectivity. Sandy mudstone mainly contains flake mica, smectite, and intergranular flake mica. Typical rock samples, including medium-grain sandstone, mudstone, and sandy mudstone, selected at the site are analyzed by $\mathrm{X}$-ray diffraction and S-M scanning laboratory. The results of the S-M scanning showed that the interior of the rock samples contains mica, montmorillonite, and illite; the clay minerals are disorderly arranged, the microcracks and pores are relatively well-developed, and the connectivity with the surrounding rock is good. The scanning results are shown in Figure 4.

The X-ray diffraction showed that the medium-grain sandstone contained quartz, sodium feldspar, and calcite crystal and shows that the total clay mineral content accounted for $20.7 \%$ of the sandstone, T. Additionally, the mineral composition of mudstone was mainly dolomite, and the total clay mineral content accounted for $19.4 \%$. The mineral composition of the sandy mudstone was mainly 


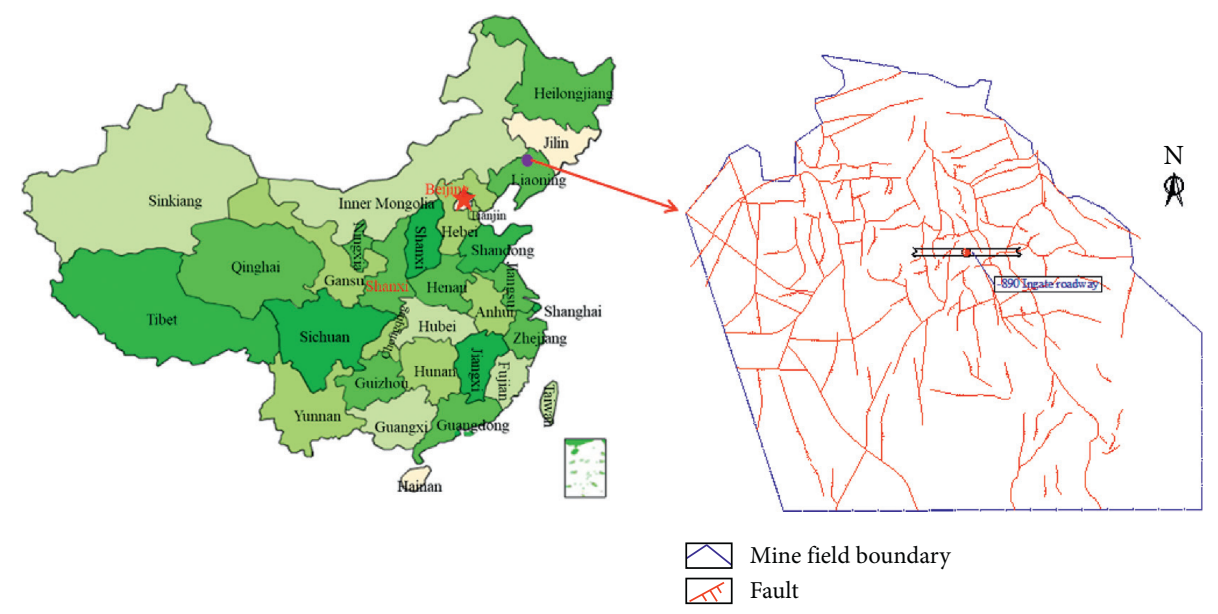

(a)

(b)

Figure 1: (a) Location of Daqiang Coal Mine, Shen Yang, China. (b) Faults distribution in a minefield.

\begin{tabular}{|c|c|c|c|c|}
\hline Geologic description & Lithology & Thickness (m) & Column & Burial depth (m) \\
\hline $\begin{array}{l}\text { Grayish white, white, argillaceous } \\
\text { cement, better cementation }\end{array}$ & Siltstone & 4 & & 958.72 \\
\hline $\begin{array}{l}\text { Grayish white, white, argillaceous } \\
\text { cement, better cementation }\end{array}$ & Siltstone & 4 & & 962.72 \\
\hline $\begin{array}{l}\text { Grayish white, white, argillaceous } \\
\text { cement, better cementation }\end{array}$ & Siltstone & 26.3 & & 989.02 \\
\hline $\begin{array}{l}\text { Grayish white, mainly feldspar and } \\
\text { gravel, argillaceous cement, hard }\end{array}$ & Glutenite & 1.7 & & 990.72 \\
\hline $\begin{array}{l}\text { Grayish white, white, argillaceous } \\
\text { cement, better cementation }\end{array}$ & Siltstone & 4 & & 994.72 \\
\hline $\begin{array}{l}\text { Grayish white, white, argillaceous } \\
\text { cement, better cementation }\end{array}$ & Siltstone & 4 & & 998.72 \\
\hline $\begin{array}{l}\text { Grayish white, white, } \\
\text { argillaceous cement }\end{array}$ & $\begin{array}{l}\text { Argillaceous } \\
\text { sandstone }\end{array}$ & 4 & & 1002.72 \\
\hline $\begin{array}{l}\text { Grayish white, white, better } \\
\text { cementation }\end{array}$ & $\begin{array}{c}\text { Coarse } \\
\text { sandstone }\end{array}$ & 4 & & 1006.72 \\
\hline $\begin{array}{l}\text { Grayish white, white, argillaceous } \\
\text { cement, better cementation }\end{array}$ & Siltstone & 4 & & 1010.72 \\
\hline
\end{tabular}

(a)

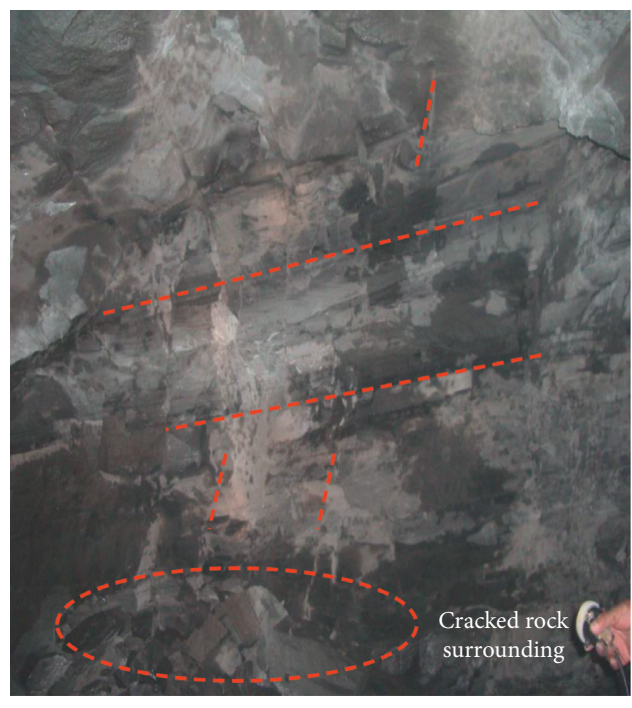

(b)

FIgURE 2: (a) Strata histogram and geologic description. (b) Surrounding rock exposure.

quartz, and the total clay mineral content accounted for $42 \%$, as shown in Tables 1 and 2 .

According to the definition and classification of engineering soft rock, as well as the on-site investigation results [18], it can be seen that the engineering soft rock type of surrounding rock of entrance roadway in the Daqiang Coal Mine is HJS composite soft rock.

\section{Numerical Analysis of the Failure Mechanism of Entrance Roadway}

3.1. Numerical Simulation Model. According to the local geology and engineering data of the roadway, a geological engineering physical elastoplastic model was generated using the ANSYS software. As shown in Figure 5, based on the Saint Venant principle, the size of the numerical simulation model has been presented using the following convention: the length, width, and height of the model are in $X$-direction $(120 \mathrm{~m}), Y$-direction $(60 \mathrm{~m})$, and $Z$-direction $(100 \mathrm{~m})$, respectively. The simulation depth is $1000 \mathrm{~m}$. The mesh is done in the ANSYS, and then the model is imported into the software FLAC3D [19].

The initial stress field is generated by applying surface force on the boundary surface of the model, which is consistent with the actual situation to the maximum extent. The overburden load is $22.5 \mathrm{MPa}$, and the vertical stress is simulated. Material failure conforms to the Mohr-Coulomb strength criterion. The physical and mechanical parameters which are used in the simulation are shown in Table 3.

The original support is in the form of an ordinary anchor bolt-net-spray + anchor cable + ordinary concrete support. In the numerical calculations, the cable unit is adopted to 


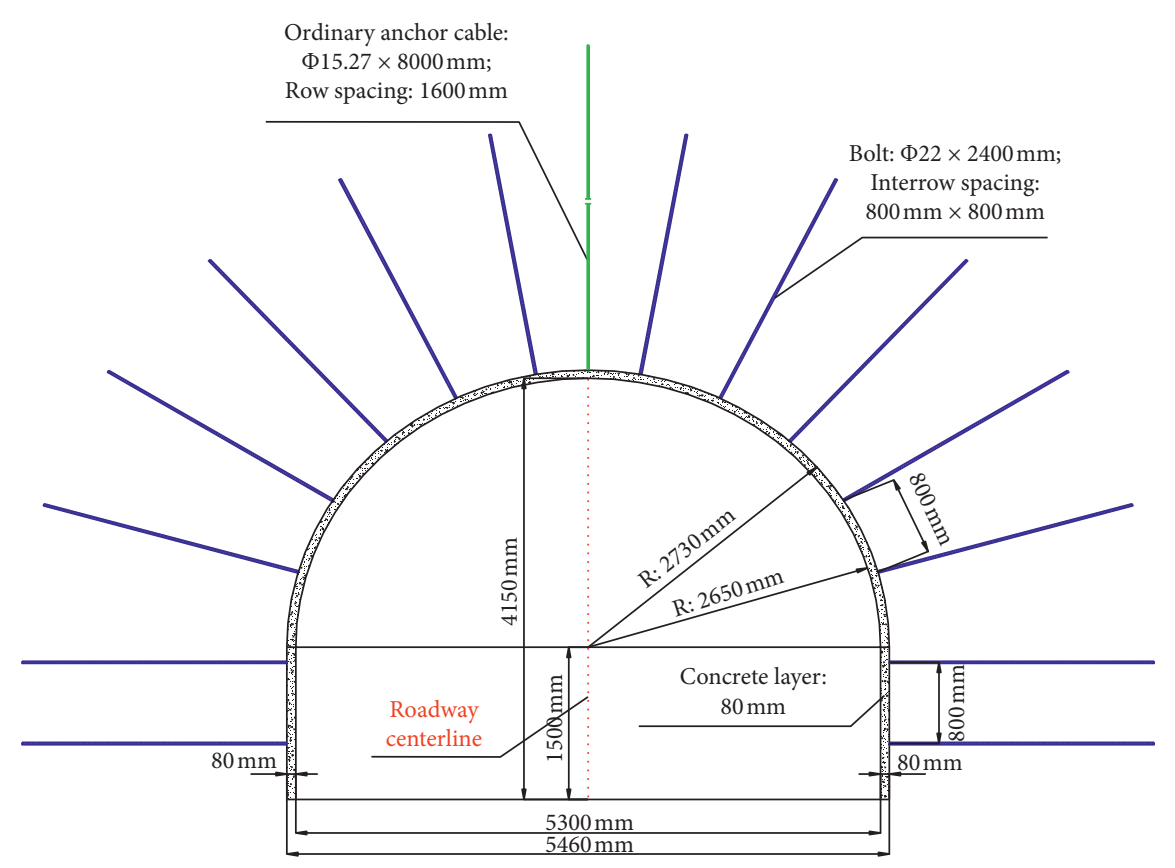

Figure 3: Original support design scheme.

simulate the left-handed threaded strong-strength steel anchor bolt and anchor cable unit, the pile unit is selected to simulate the bottom corner anchor bolt, and the FISH language editing program is selected to simulate the force characteristics of the anchor bolts.

Partial excavation is adopted where the shaft is mined first and then the entrance roadway was excavated. A measuring point is set at the entrance roadway $15 \mathrm{~m}$ away from the shaft, and the displacement and stress distribution at the measuring point are monitored, respectively.

\subsection{Analysis of Numerical Simulation Results}

3.2.1. Stress Field Distribution. The distribution of horizontal and vertical stress is shown in Figure 6. Influenced by the original ground stress field and the excavation disturbance, the stress concentration area appears around surrounding rock. The stress field of surrounding rock presents the characteristics of an asymmetric distribution.

Moreover, with the decrease in the surrounding rock stress, the stress concentration area is transferred to the deep surrounding rock. Maximum stress is concentrated at about $10 \mathrm{~m}$ to $12 \mathrm{~m}$ away from the center of the roadway, and the concentration coefficient is about 1.2-1.3. However, the stress at the measuring point is in a relatively reduced area.

The variation rule of the surrounding rock stress field at the measuring point is shown in Figure 7. When excavating to the monitoring section, the vertical stress at the measuring point increases. Under the influence of the excavation unloading and support system, the stress at the measuring point will decrease first and then increase (as shown in Figure $7(\mathrm{a})$ ). However, the distribution of the horizontal stress field is quite different from that of the vertical stress. Figure 7(b) shows that the stress value of the roof and the right side decreases first and then increases. However, the stress at the bottom plate and the left side follows a continuous decreasing trend.

3.2.2. Displacement Field Distribution. Under the original support system, the deformation of the surrounding rock is large. Particularly, the lifting capacity of the bottom plate can reach $483 \mathrm{~mm}$ (as shown in Figure 8(a)). The deformation of the two sides presents an asymmetric distribution. The left side deformation is concentrated in the lower middle section of the straight wall, while the right-side deformation is mainly in the middle of the straight wall.

3.2.3. Plastic Zone Distribution. Figure 9 shows that the plastic zone is widely distributed. The maximum radius of the plastic zone under the original support is $13.87 \mathrm{~m}$, which appears at the roof. The radii of the plastic zone of the floor plate and two sides are $9.97 \mathrm{~m}$ and $10.79 \mathrm{~m}$, respectively. The plastic zone exceeds the effective range of the original support system. Therefore, the surrounding rock presents a variety of yield states. Particularly, the surrounding rock of the floor plate presents a composite state of tension and shear, which aggravates the floor damage degree and makes the floor heave amount significant. The surrounding rock at the intersection of the two sides and the floor is always in a state of shear stress, which reflects the transmission path of the bottom heave stress.

3.3. Failure Mechanism Analysis. On-site investigations, laboratory experiments, and numerical simulation analysis of the actual engineering reveal that the main causes for large deformation of the surrounding rock of the roadway are as follows: 


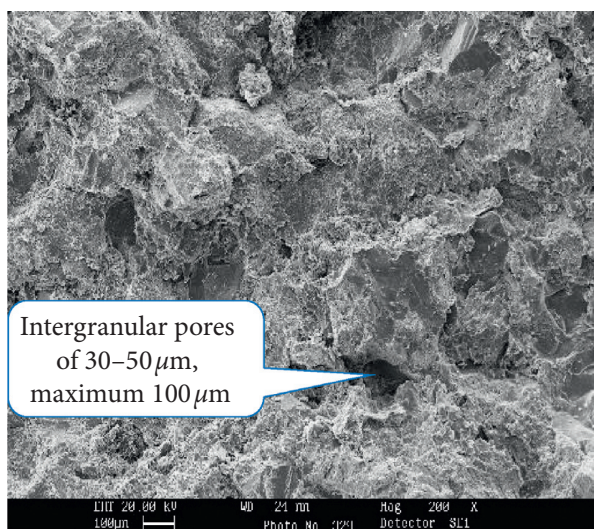

(a)

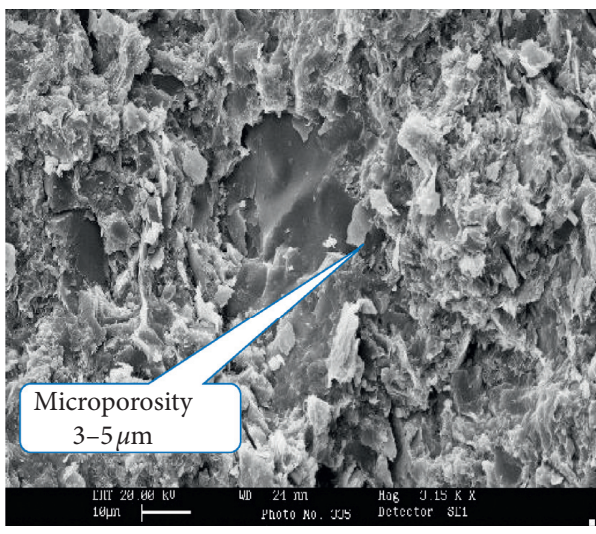

(c)

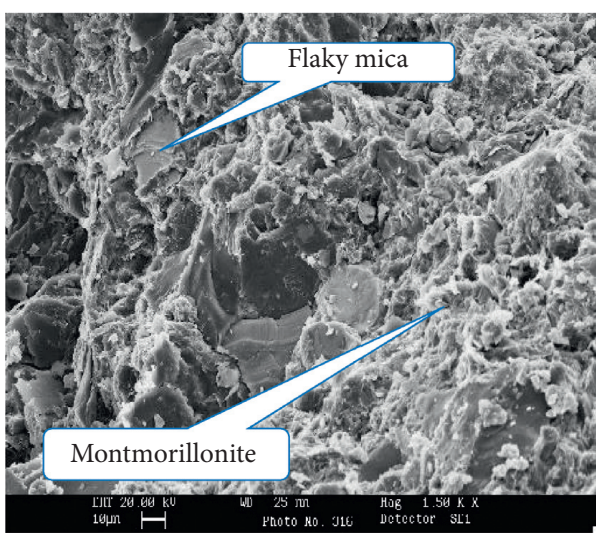

(e)

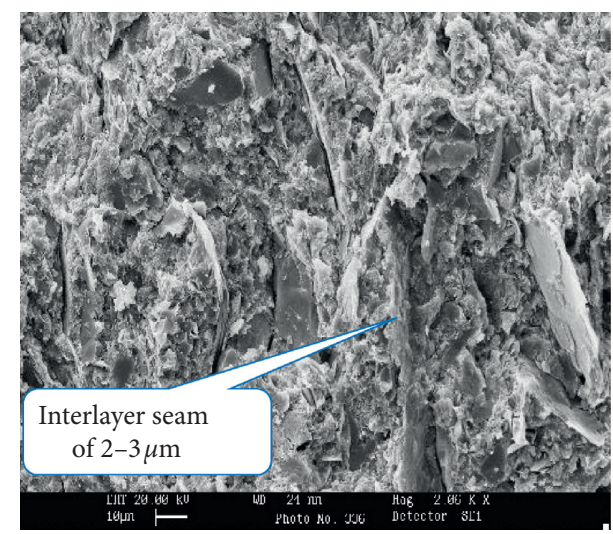

(b)

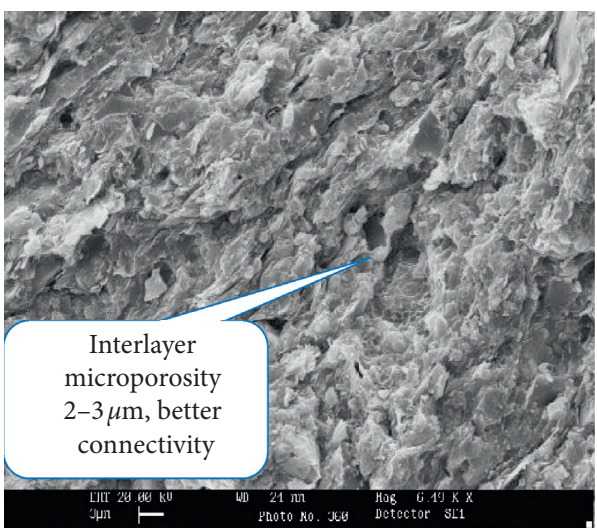

(d)

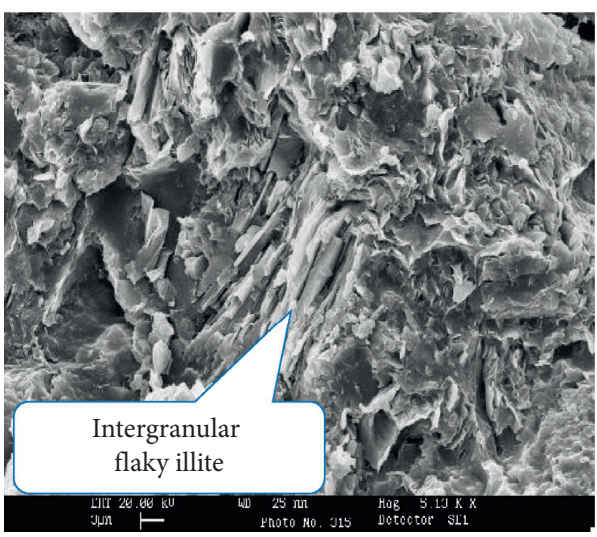

(f)

FigURE 4: S-M scanning results. (a) Medium-grain sandstone (500 times magnification). (b) Medium-grain sandstone (1000 times magnification). (c) Mudstone (2000 times magnification). (d) Sandy mudstone (2000 times magnification). (e) Sandy mudstone (2000 times magnification). (f) Mudstone (3000 times magnification).

(1) The large buried depth and high geostatic stress, the high-stress concentration of the surrounding rock caused by the geological structure and excavation, the superposition of high stress, and the influence of faults further increase the complexity of the surrounding rock stress field of the roadway. The prominent contradiction between the complex highstress field and the low-strength surrounding rock causes the surrounding rock to undergo multiple discontinuous and continuous deformation processes, which further increases the deformation and failure extent of the surrounding rock.

(2) The content of clay minerals in the rock of the surrounding strata accounts for $19.4 \% \sim 42 \%$, and that of the mixed layer of illite and montmorillonite accounts for 30\% 35\%; the internal joints, crack development, and conductivity of the rock mass are good, and it can easily absorb water and soften, which furtherly reduces the strength of the 
TABLE 1: Whole-rock mineral X-ray diffraction analysis.

\begin{tabular}{|c|c|c|c|c|c|c|c|c|c|}
\hline \multirow[b]{2}{*}{ Number } & \multirow[b]{2}{*}{ Sample number } & \multicolumn{7}{|c|}{ Mineral type and content (\%) } & \multirow[b]{2}{*}{$\begin{array}{l}\text { Total clay mineralcontent } \\
(\%)\end{array}$} \\
\hline & & Quartz & $\begin{array}{l}\text { Potash } \\
\text { feldspar }\end{array}$ & $\begin{array}{l}\text { Sodium } \\
\text { feldspar }\end{array}$ & Plagioclase & Calcite & Dolomite & Pyrite & \\
\hline 1 & $\begin{array}{l}\text { Medium-grain } \\
\text { sandstone }\end{array}$ & 22.8 & - & 27.1 & - & 29.4 & - & - & 20.7 \\
\hline 2 & Mudstone & 14.5 & 7.7 & 10.7 & - & - & 44.3 & 3.4 & 19.4 \\
\hline 3 & Sandy mudstone & 32.9 & - & 24.7 & - & 0.4 & - & - & 42.0 \\
\hline
\end{tabular}

TABLE 2: Clay mineral X-ray diffraction analysis results.

\begin{tabular}{|c|c|c|c|c|c|c|c|c|c|}
\hline \multirow[b]{2}{*}{ Number } & \multirow[b]{2}{*}{ Sample number } & \multicolumn{5}{|c|}{ Relative content of clay minerals (\%) } & \multicolumn{3}{|c|}{ Mixing ratio $(\% / S)$} \\
\hline & & Smectite & $\begin{array}{l}\text { Illinois/ } \\
\text { smectite }\end{array}$ & Illinois & Kaolinite & Chlorite & $\begin{array}{l}\text { Chlorite/ } \\
\text { smectite }\end{array}$ & $\begin{array}{l}\text { Illinois/ } \\
\text { smectite }\end{array}$ & Chlorite/smectite \\
\hline 1 & $\begin{array}{l}\text { Medium-grain } \\
\text { sandstone }\end{array}$ & - & 40 & - & 32 & 28 & - & 35 & \\
\hline 2 & Mudstone & - & - & 71 & 29 & - & - & - & - \\
\hline 3 & Sandy mudstone & - & 40 & 23 & 18 & 19 & - & 30 & \\
\hline
\end{tabular}

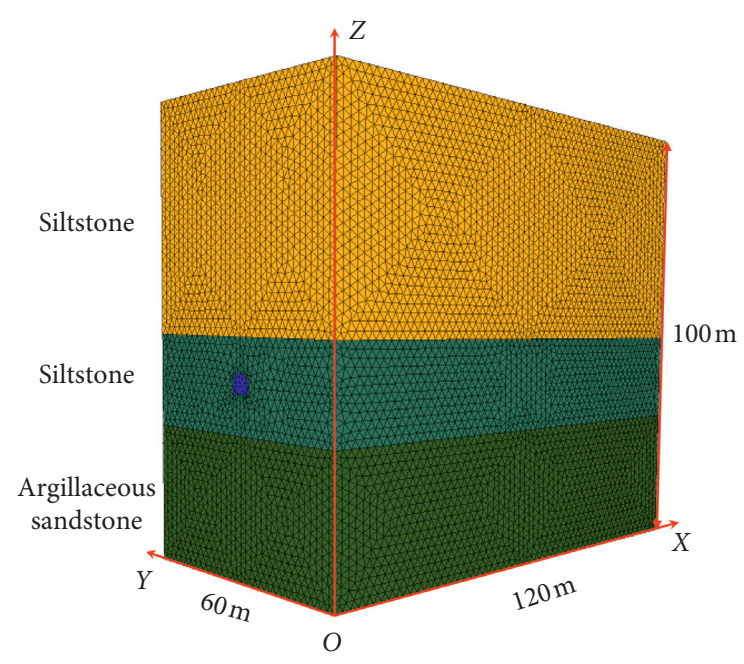

(a)

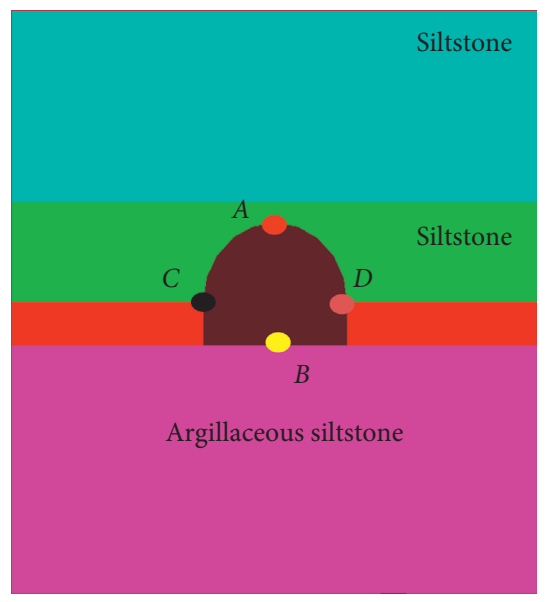

(b)

Figure 5: Numerical analysis. (a) Numerical calculation model. (b) Monitoring point layout.

surrounding rock. The minefield structure is dominated by the fault structure, which increases the complexity of the engineering rock mass.

(3) Although the original support system adopts an anchor net spray + anchor cable + ordinary concrete joint support, these supporting materials are all small deformation supporting materials, which cannot release the plastic deformation energy accumulated in the surrounding rock. Moreover, the stress of the support system is easy to gather, which causes the failure of the local support system, which consequently causes the overall failure. Therefore, the arch-like bearing structure of the original support system cannot be formed. In addition, due to the influence of complex high-stress field and rheological characteristics of the rock mass, the development of harmful fractures in surrounding rock cannot be controlled effectively [13], which finally leads to the large deformation of the surrounding rock.

\section{Transformation Analysis of the Stability Deformation Mechanism}

4.1. Mechanism of Soft Rock Deformation. Given the above analysis, the rocks surrounding the entrance consist mostly of mudstone rock formations, and the results of $\mathrm{X}$-ray diffraction and electron microscope scanning analysis show high clay mineral content in the surrounding rock. Moreover, clay minerals are mainly composed of hydrophilic montmorillonite and illite. The mudstone adsorbs moisture from the air and water, causing large deformation by expansion. The vertical 
TABLE 3: Physical-mechanical parameters of rocks.

\begin{tabular}{lcccccc}
\hline Lithology name & $\begin{array}{c}\text { Bulk density } \\
\left(\mathrm{kg} \cdot \mathrm{m}^{-3}\right)\end{array}$ & $\begin{array}{c}\text { Bulk modulus } \\
(\mathrm{GPa})\end{array}$ & $\begin{array}{c}\text { Shear modulus } \\
(\mathrm{GPa})\end{array}$ & $\begin{array}{c}\text { Tensile strength } \\
(\mathrm{MPa})\end{array}$ & $\begin{array}{c}\text { Adhesion } \\
(\mathrm{MPa})\end{array}$ & $\begin{array}{c}\text { Angle of internal friction } \\
\left({ }^{\circ}\right)\end{array}$ \\
\hline Siltstone & 2510 & 4.8 & 2.8 & 1.2 & 3.0 & 30 \\
Siltstone & 2530 & 4.8 & 2.8 & 1.2 & 3.0 & 30 \\
$\begin{array}{l}\text { Argillaceous } \\
\text { sandstone }\end{array}$ & 2320 & 2.4 & 1.1 & 0.6 & 1.2 & 27 \\
\hline
\end{tabular}

$$
\begin{aligned}
& Z Z \text { stress } \\
& \text { Plane: on } \\
& \begin{array}{l}
6.1950 E+04 \\
0.0000 E+00 \\
-2.5000 E+06 \\
-5.0000 E+06 \\
-7.5000 E+06 \\
-1.0000 E+07 \\
-1.2500 E+07 \\
-1.5000 E+07 \\
-1.7500 E+07 \\
-2.0000 E+07 \\
-2.2500 E+07 \\
-2.5000 E+07 \\
-2.7500 E+07 \\
-3.0000 E+07 \\
-3.0923 E+07
\end{array}
\end{aligned}
$$

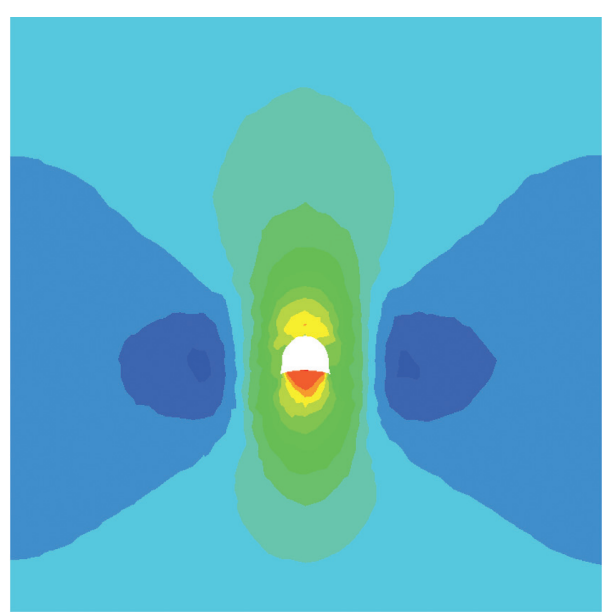

(a)

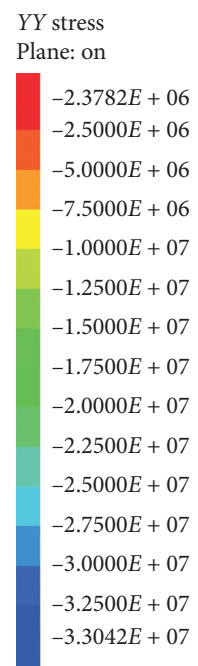

Plane: on

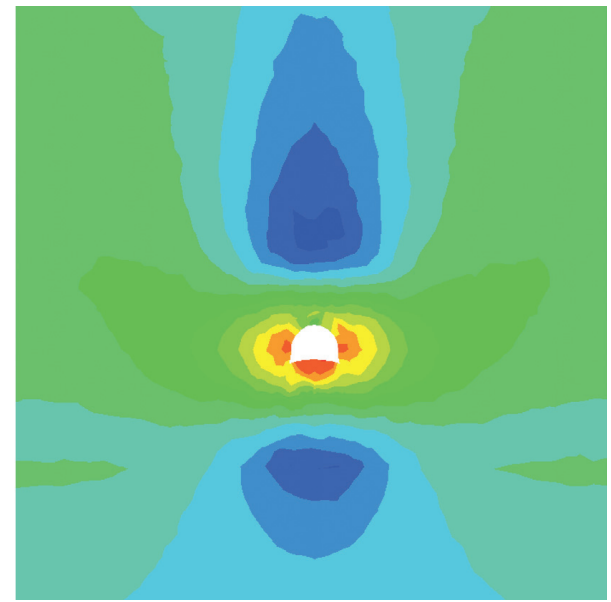

(b)

FiguRE 6: Stress field distribution of surrounding rock under original support (unit: Pa): (a) horizontal stress; (b) vertical stress.

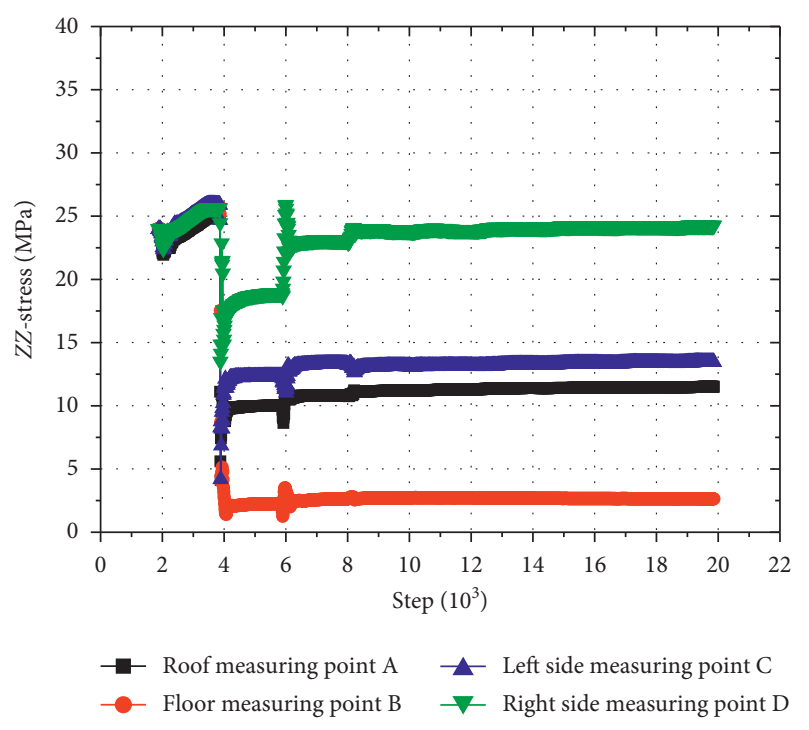

(a)

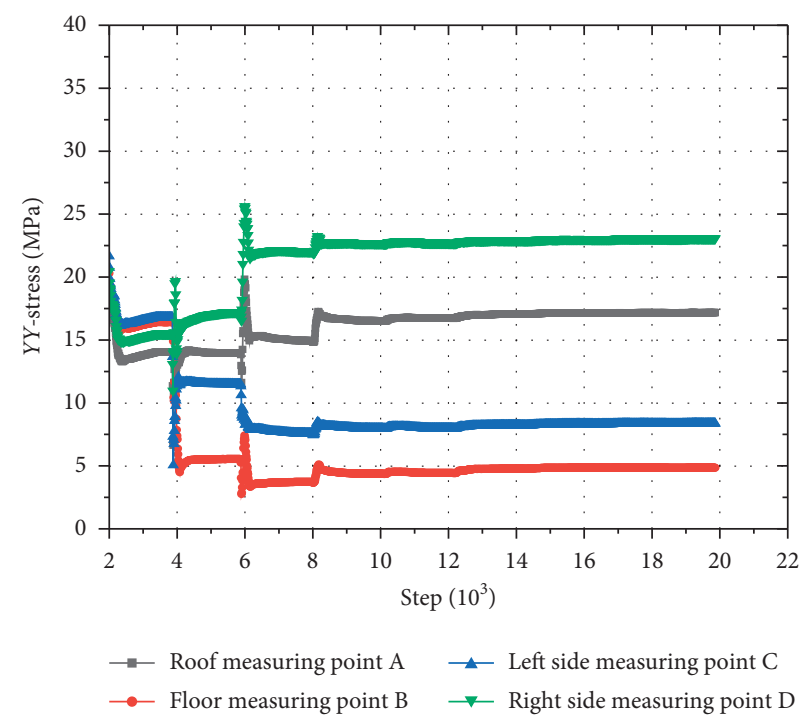

(b)

Figure 7: The stress curve at the measuring point: (a) horizontal stress; (b) vertical stress.

stress due to the roadway position is as high as $27 \mathrm{MPa}$, as it is also affected by excavation disturbances. Due to the superposition of structural stress, the concentrated stress level is higher. Meanwhile, many faults in the minefield and the internal bedding and fissures of the surrounding rock are developed. In summary, the deformation mechanics of the surrounding rock for the entrance roadway can be summarized as type $\mathrm{I}_{\mathrm{AB}} \mathrm{II}_{\mathrm{AB}} \mathrm{III}_{\mathrm{ABC}}$ [11]. 


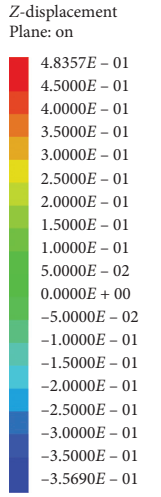

$5690-01$

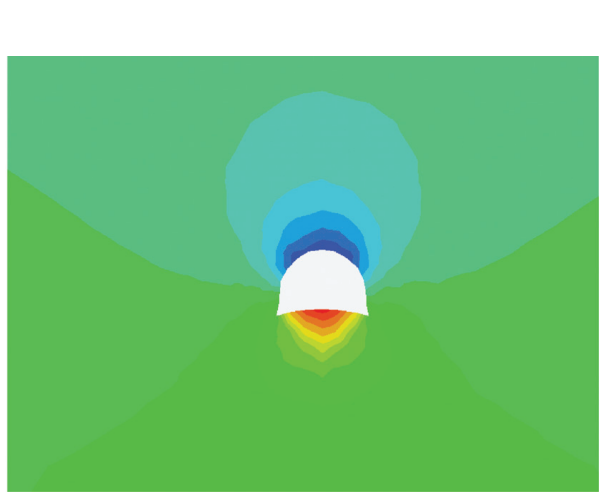

(a)
$Y$-displacement Plane: on
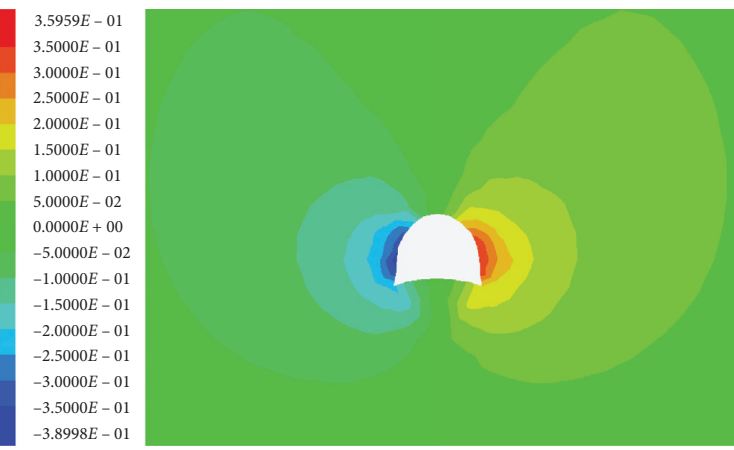

(b)

FiguRE 8: Displacement field distribution of surrounding rock under original support (unit: m): (a) vertical displacement; (b) horizontal displacement.

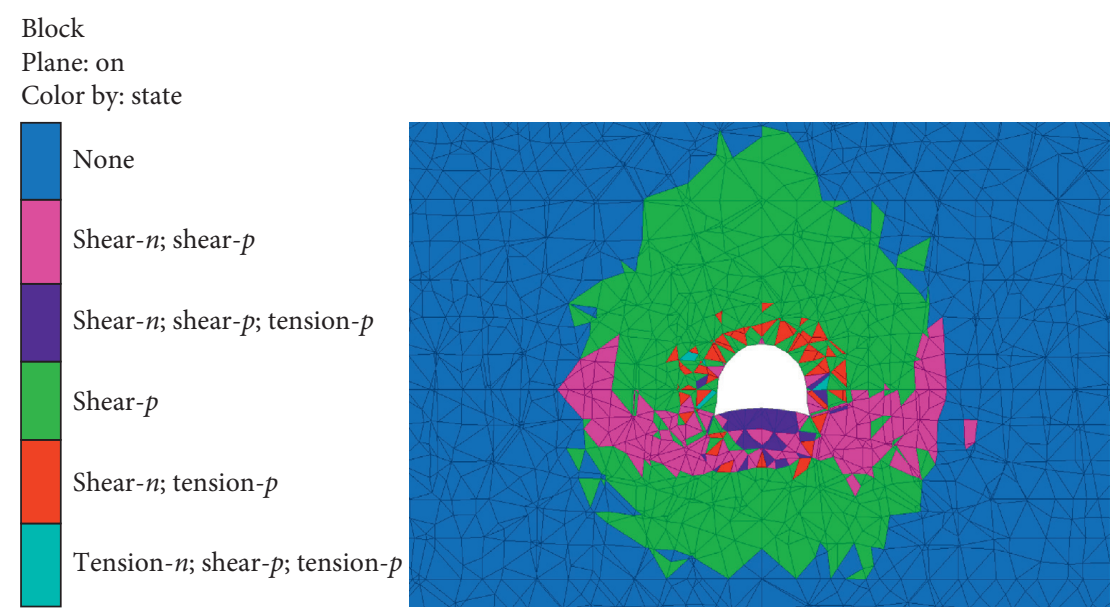

FIGURE 9: Plastic zone distribution of surrounding rock under original support.

4.2. Stability Control Transformation Strategy. The key to the stability control of complex soft rock roadways is the transformation of the complex deformation mechanism of soft rock into a single deformation mechanism in order to successfully support the soft rock roadway. Therefore, the following stability control transformation strategies are adopted in this paper:

(1) Type $I_{A B}$ : based on strengthening the surrounding rock with high prestress. This concentrates the plastic deformation energy in the surrounding rock and enables a controlled-release.

(2) Type $\mathrm{II}_{\mathrm{AB}}$ : the anchor net-cable coupling support improves the strength of the surrounding rock and the integrity of the support system and the surrounding rock of the roadway. The bottom corner anchor bolt control technology cuts the plastic deformation slip line of the bottom plate. Meanwhile, the three-dimensional flexible layer truss support technology is adapted to couple the active and passive support. Further, the unstable type of $\mathrm{II}_{\mathrm{AB}}$ is transformed into a stable type $\mathrm{II}_{\mathrm{B}}$ [12]. The process of stability transformation control countermeasures is shown in Figure 10.

(3) Type $\mathrm{III}_{\mathrm{ABC}}$ : three-dimensional bolt optimization technology improves the bearing capacity of the frontal surrounding rock. Key parts of the anchor cable support control the surrounding rock differential deformation.

\section{Stability Control Strategy and Numerical Simulation Analysis}

5.1. Mechanism of Constant-Resistance Rigid-Flexible Coupling Support. Theoretical calculations show that the critical depth of deep engineering in the Da Qiang Coal Mine is $552 \mathrm{~m}$, the buried depth of the entrance is about $1000 \mathrm{~m}$, nearly twice the critical depth, and the difficulty factor $D_{f}$ is 1.8 [20]. Currently, the soft rock at the Da Qiang Coal Mine is in the state of large nonlinear deformation. Therefore, a nonlinear large deformation design should be adopted, with 


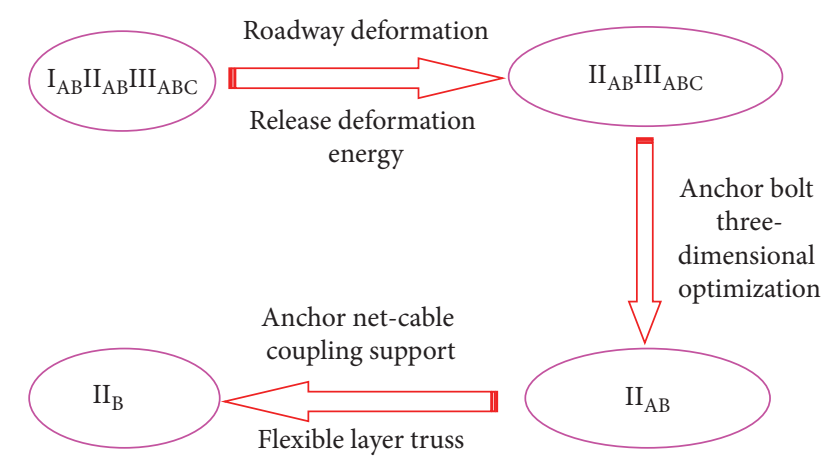

Figure 10: Composite deformation mechanisms of the transformation process.

the support method adopting the coupling support technology [15].

Therefore, this paper proposes the CRRFC control strategy with the CRLDAB (the constant-resistance and large deformation anchor bolt)/CRLDAC (the constantresistance and large deformation anchor cable)-layer truss as the core. Its mechanism is as follows.

\subsubsection{CRLDAB Net Spray + CRLDAC to Control Differential} Deformation. CRLDAB net spray is adopted to strengthen and seal the surrounding rock, which can minimize the contact time between water and the surrounding rock. The atypical anchor bolt, CRLDAB, can provide higher prestress (typically $180 \mathrm{kN}$ ). The spread range of the prestress in the bolt support is improved, and hence, the integrity of the surrounding rock can be effectively guaranteed. In particular, CRLDAB has the unique mechanical characteristics of large deformation, which helps in realizing the integrated function of pressure relief and support [15]. Simultaneously, CRLDAB net spray reduces the asymmetric damage of the surrounding rock.

The CRLDAC support can effectively transfer the excessively high stress on the surrounding rock to the deeper parts, ensuring that the rock mass in the anchorage range is under pressure. This prevents the harmful development of joints and cracks in the surrounding rock and improves the integrity of the surrounding rock, which can maximize the role of the shaped bearing arch. Furthermore, CRLDAC makes for the best coupling state of the bolt cable support system through its deformation [15-18].

\subsubsection{Bottom Corner Reinforcement Technology to Control} Floor Heave. The failure of the floor is generally caused by the composite superposition of tensile stress and shear stress. Moreover, the deformation of the surrounding rock of the bottom plate induces the deformation of the two sides. Therefore, the bottom angle grouting anchor pipe can improve the shear resistance of rock strata and cut off the stress transmission path of the bottom plate. Furthermore, the stress state of the floor and surrounding rock is improved, and the malignant development of the plastic zone is effectively controlled. Simultaneously, this type of support allows a certain degree of deformation of the floor, and a certain amount of deformation is allowed over time, and the C40 concrete is poured on the floor.

5.1.3. Rigid-Flexible Coupling Support to Improve the Stability of Surrounding Rock as a Whole. The rigid-flexible coupling support is mainly composed of a rigid layer and a flexible layer. The flexible layer is composed of an anchor net that supports the rock mass. The rigid layer consists of flexible trusses and a subsequent spray of permanent concrete. Meanwhile, a certain amount of clearance is reserved between the rigid layer and the flexible layer, which can release differential deformation energy in the anchoring to the surrounding rock. By releasing the deformation energy, a support-surrounding rock bearing structure with internal plastic working state region and external elastic working state region is realized.

As the surrounding rock continues to deform, the permanent supporting concrete is sprayed immediately when the surrounding rock makes contact with the truss to limit the deformation of the surrounding rock. At this point, the whole support system enters into the working state, and the local deformation energy will be decomposed into the adjacent support components. Furthermore, the variable performance decreases continuously to prevent the destruction of the surrounding rock [19], and thus, the stability of the surrounding rock of the roadway is guaranteed.

\subsection{The Core Technology of the CRRFC Support}

5.2.1. The CRLDAB Support Technology. The CRLDAB and CRLDAC are the large deformation anchor bolt and cable specially developed to control large deformation occurrences in the soft rock roadway. Their structures are shown in Figure 11. CRLDAB consists of a nut, tray, constantresistance device through the tray, connecting members, and the bolt [21]. Similarly, CRLDAC consists of a nut, tray, constant-resistance device through the tray, and the cable. Both CRLDAB and CRLDAC have characteristics of high constant resistance, high pretension, and large deformation, and their deformation is generated by the slip of the inner cone of the constant resistor relative to the casing. The CRLDAB is used in the shallow surrounding rock to form the structure of compression arch, which could ensure the stability of the shallow surrounding rock. The compression arch formed by the shallow CRLDAB is suspended in the deep stable surrounding rock by the CRLDAC to further ensure the stability of the roadway. Reference [14] shows the schematic diagram of CRLDA.

To verify the unique mechanical properties of the CRLDA, the laboratory static tensile test is carried out. The diameter of the constant-resistance device is $32 \mathrm{~mm}$ and the length is $600 \mathrm{~mm}$. Laboratory test results show that the tensile capacity of the CRLDA can be divided into three stages (as shown in Figure 12).

(i) Stage I: with the increase of tensile stress, the tensility increases; the range of tensile was $0 \sim 30 \mathrm{~mm}$; 


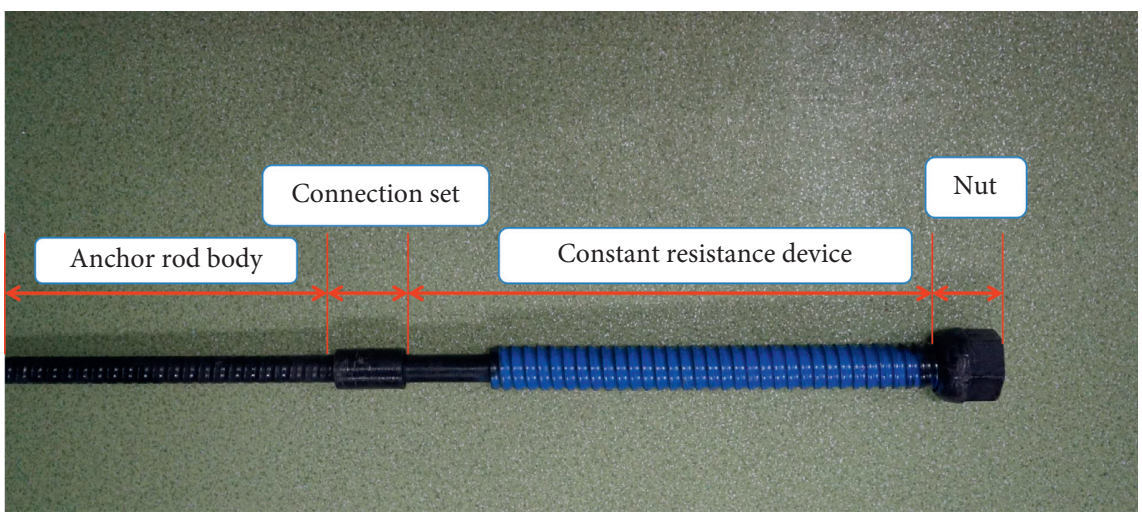

FIgURE 11: The structure of CRLDA [21].

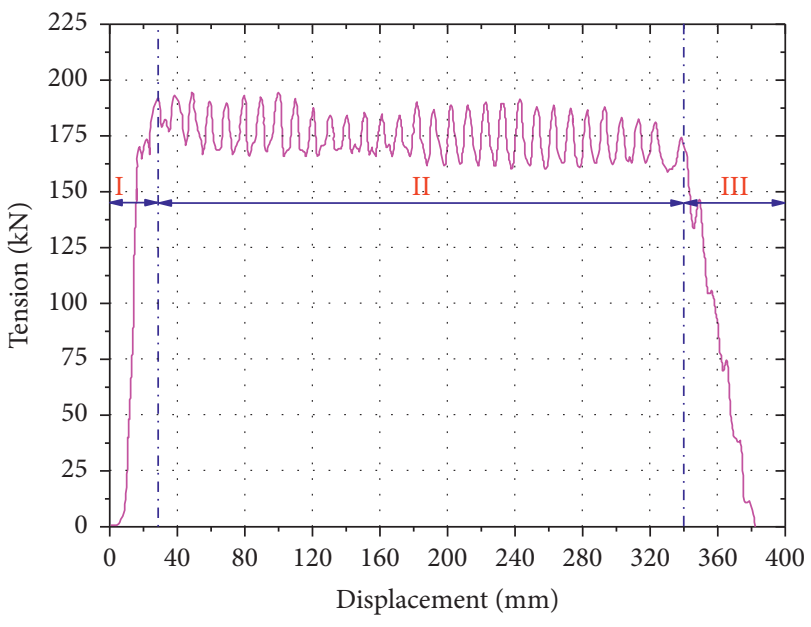

Figure 12: The force and displacement curve of CRLDAB.

this is the elastic working stage, which is similar to the ordinary bolt.

(ii) Stage II: the deformation of the CRLDA increases, up to $345 \mathrm{~mm}$, but the tension force stabilizes between $160 \mathrm{kN}$ and $194 \mathrm{kN}$; this is the constant-resistance working stage, and its stroke is $305 \mathrm{~mm}$.

(iii) Stage III: the curve of this stage shows that although the deformation of the CRLDA increases, its supporting efficiency is lost. However, contrary to the sudden fracture of an ordinary bolt, the CRLDAB demonstrates a slow failure process. [14]

The theoretical model of CRLD bolts can be written as

$$
P_{0}=2 \pi f I_{s} I_{c} \text {, }
$$

where $P_{0}$ is the overall resistance, $f$ is the frictional coefficient, $I_{s}$ is the constant-resistance device elastic constant, and $I_{c}$ is the cone geometrical constant.

Comprehensive analysis reveals that the CRLDAB can maintain high constant resistance and produce large deformation. It overcomes the problem of traditional bolts tending to accumulate and break when the energy increases with the amount of deformation.
The CRLDAB firstly strengthens the surrounding rock through high pretension, limiting the development of joint fissures in the surrounding rock. When the stress applied to the supporting body exceeds the pretension and reaches the requirement for the working state of the CRLDAB, the cone connected to the bolt is displaced relative to the casing, releasing strong deformation energy to the surrounding rock. However, in the process of energy release, the surrounding rock is in a relatively stable compression state due to the high constant resistance. With the continuous release of energy, the stress acting on the supporting body gradually decreases; at this time, the CRLDAB remains in a constant-resistance state, which improves the stability of the surrounding rock.

\subsubsection{Three-Dimensional Rigid-Flexible Truss Support} Technology. Three-dimensional flexible truss support technology is mainly composed of rigid support materials, such as an I-beam, steel plate, and bolt. The I-beam is used to construct a single-layer truss employing a connecting rod and plate. Connecting members then connect the singlelayer truss with the three-dimensional double-layer truss in the lateral direction (as shown in Figure 13). This design integrates the bending and torsion resistance of the steel frame to provide tensile, compressive, or shear resistance through structural design.

Generally, the deformation of the surrounding rock often initiates from a certain position. If this deformation is not effectively controlled, it can potentially destroy the roadway. However, when trusses support the surrounding rock, the high local stress $(F)$ acting on the truss support system is decomposed into tensile stress $\left(f_{1}, f_{2}, f_{3}\right.$, $\ldots, f_{6}$ ) acting on the whole truss system, which is transferred along the roadway direction and gradually decreases (as shown in Figure 14). Simultaneously, considering the support reaction force $(P)$ provided by the truss system, the stress level acting on the truss system is further weakened, so that the bearing structure formed by the surrounding supporting rock experiences more uniform stress.

5.3. Stability Control Strategy for Deep Well Soft Rock Roadways. Based on the above analysis of surrounding rock 

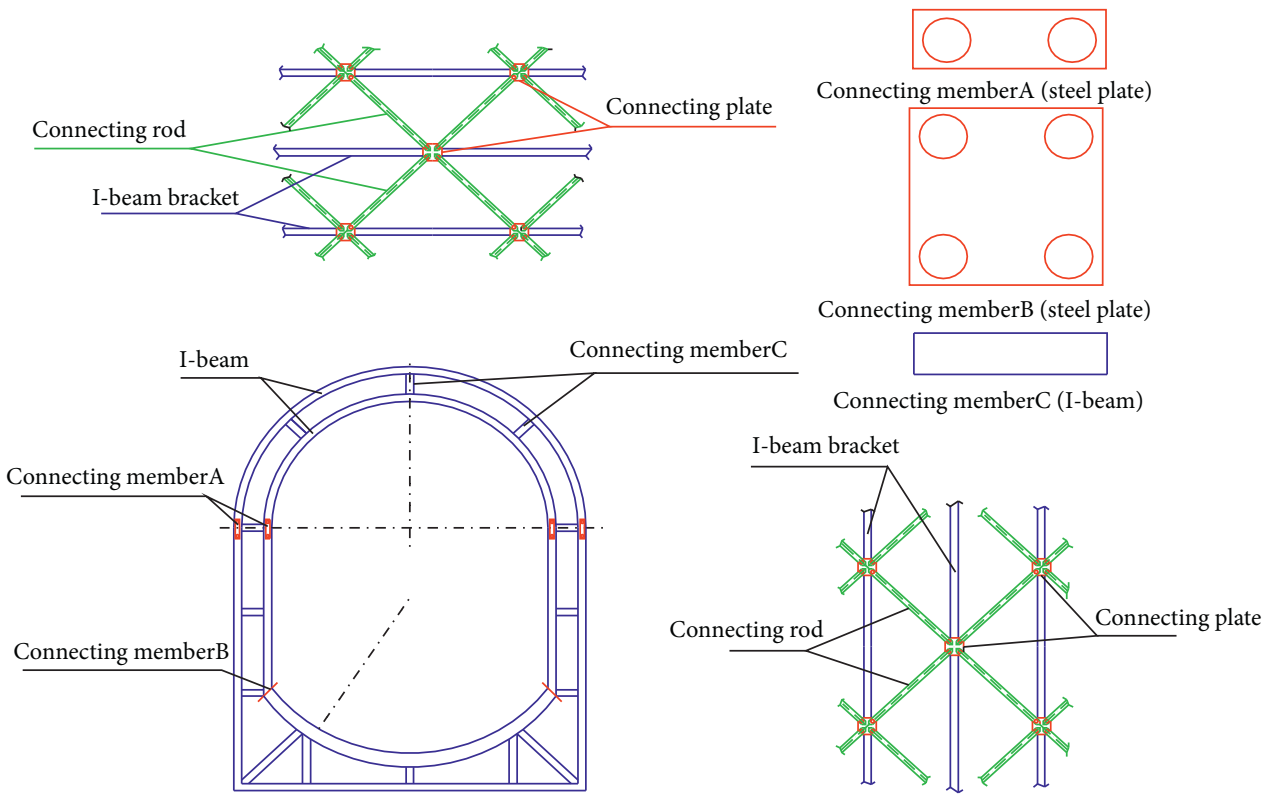

FIGURE 13: Schematic diagram of the flexible truss structure.

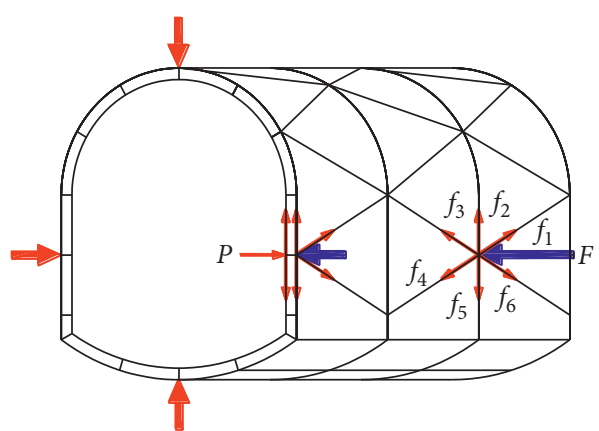

FIgURE 14: Stress analysis of a flexible truss support system.

deformations, failure mechanisms, and the CRRFC support mechanism, the support design scheme for deep soft rock roadway has been developed. The design of the CRRFC support is shown in Figure 15, and the support design parameters are as follows:

(1) Anchor bolt: $\varphi 20 \mathrm{~mm} \times 2400 \mathrm{~mm}$ CRLDAB is adopted with the following specifications: diameter of the constant resistor $-32 \mathrm{~mm}$; length $-600 \mathrm{~mm}$; and interrow spacing $-800 \times 800 \mathrm{~mm}$, arranged in a circular pattern. The pretightening force is not less than 15 tons.

(2) Anchor cable: $\varphi 15.24 \mathrm{~mm} \times 8000 \mathrm{~mm}$ CRLDAC is adopted with the following specifications: diameter of the constant resistor $-45 \mathrm{~mm}$; length $-800 \mathrm{~mm}$; length of the anchor cable $-8000 \mathrm{~mm}$; length of the exposed cable $-300 \mathrm{~mm}$; interrow spacing $-1600 \times 1600 \mathrm{~mm}$, in 3 by 3 arrangement. The pretightening force is not less than 28 tons.
(3) Metal net: welded from $6.5 \mathrm{~mm}$ steel bars, the net size is $1700 \times 900 \mathrm{~mm}$, and the mesh size is $100 \times 100 \mathrm{~mm}$.

(4) Bottom corner anchor bolt: $\varphi 43 \mathrm{~mm}$ seamless steel pipe is adopted, interpolated with steel bars, and grouted; the row spacing is $500 \mathrm{~mm}$.

(5) Concrete: the initial spray thickness is $60 \mathrm{~mm}$. According to the monitoring results, after the deformation of the surrounding rock stabilizes, it is resprayed until contact with the steel frame. 1 2 months after the completion of the support, permanent support is implemented through a permanent spray of concrete to cover the steel frame, and the thickness of the outer protective layer of the steel frame is maintained at $80 \mathrm{~mm}$, with pouring concrete strength grade of $\mathrm{C} 40$.

(6) Floor arch: pouring concrete, initial pouring of $100 \mathrm{~mm}$, and permanent pouring to the floor design height of the floor, with pouring concrete strength grade of $\mathrm{C} 40$.

(7) Three-dimensional flexible layer truss: the material is a 12\# mining I-beam. Each bracket is divided into four sections, and $\mathrm{M} 20 \times 70$ bolts connect the top arch brackets through the splint connecting members. The wall brackets and the floor arch brackets are connected through a balanced force interface connecting plate and $\mathrm{M} 20 \times 70$ bolts. The material of the balanced force interface connecting plate is A3 steel, with a thickness of $16 \mathrm{~mm}$, welded according to the position shown in the design drawings; all are continuous welds, with a weld height of $10 \mathrm{~mm}$.

(8) Pull rod: the brackets are connected by the equilateral 9\# angle steel rod and the welded A3 steel 


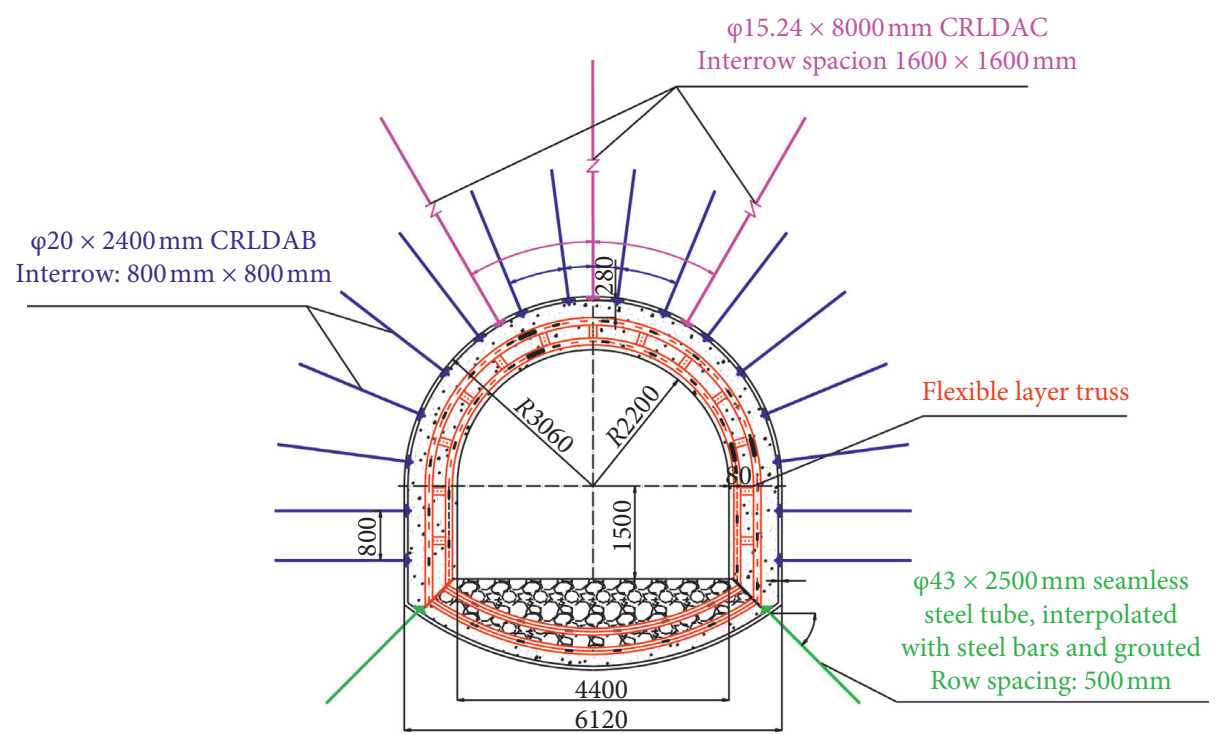

Figure 15: Design scheme of the CRRFC support (un: mm).

connecting members, and the spacing between flat steel welding positions is $800 \mathrm{~mm}$. Among them, the top arch and the two-sided brackets are connected in a triangular shape, and the bottom bracket has a straight rod connection, which was connected by M18 $\times 70$ bolts.

5.4. Numerical Simulation Analysis. Before applying the proposed scheme to real-world engineering applications, a numerical simulation is conducted to test the feasibility of the CRRFC support scheme. To achieve a reasonable simulation effect, the shell unit is used to simulate the truss support in the numerical model. Based on the cable unit in FLac3d, the built-in language FISH is used to realize the mechanical properties of the CRLDAB and CRLDAC.

Compared with the original support, the stress concentration of the surrounding rock under the new support scheme is greatly reduced, and the surrounding rock stress is transferred to the shallow part. The simulation results show that the bearing capacity of the surrounding rock has been effectively improved. The displacement of the roof, two sides, and floor plates were $53 \mathrm{~mm}, 58 \mathrm{~mm}$, and $150 \mathrm{~mm}$, respectively. Compared with the original support, the deformation of surrounding rock is reduced by $69 \% \sim 85 \%$, which is within the allowable controllable range.

The distribution of the surrounding rock plastic zone under the new support is shown in Figure 16(e). Under the new support, the maximum radius of the plastic zone is $6.13 \mathrm{~m}$, which appears on the floor plate. Compared with the original support, the radius of the plastic zone at the floor plate is reduced by about $38 \%$. In particular, the effective control of the floor position plasticity weakens its tendency to develop toward the two sides of the roadway. The whole rock in the plastic zone shows shear state, and only a small number of tension shear units exist, mainly in the bottom plate. The comprehensive analysis shows that the application of the anchor pipe for anchor grouting can effectively cut off the transfer path of the bottom heave stress, and the control effect of the CRRFC support is significant.

\section{Engineering Applications}

To further confirm the feasibility of the CRRFC support technology, a monitoring station is set up along the construction roadway to monitor the deformation of the surrounding rock. Measurement points A and B are located at key positions along the roadway roof and floor, respectively, while measurement points $C$ and $D$ are located on the sides at the height of $750 \mathrm{~mm}$ from the floor, as shown in Figure 17(a).

After 130 days of continuous monitoring, the data of each measuring point are sorted out, and curves are drawn, as shown in Figure 17(b), which can accurately reflect the development law of surrounding rock displacement and support effect. After the application of the new technology, the subsidence of the roadway roof, the shrinking of the two sides, and the floor heave are $35 \mathrm{~mm}, 16 \mathrm{~mm}$, and $14.5 \mathrm{~mm}$, respectively.

According to the deformation rate of the surrounding rock, the process of deformation of the surrounding rock can be divided into four phases. During the first stage, the surrounding rock deformation is in the acceleration stage, and the maximum mean value of the deformation rate is $1.4 \mathrm{~mm} / \mathrm{d}$. At this stage, the surrounding rock deformation is the largest, which is mainly affected by the excavation disturbance and the adjustment of the surrounding rock stress field.

During the second stage, the surrounding rock deformation is in the fluctuating stage. The deformation of surrounding rock gradually tends to become stable under the constant-resistance rigid-flexible coupling support.

During the third stage, the surrounding rock deformation enters the acceleration stage again, but the rate of 


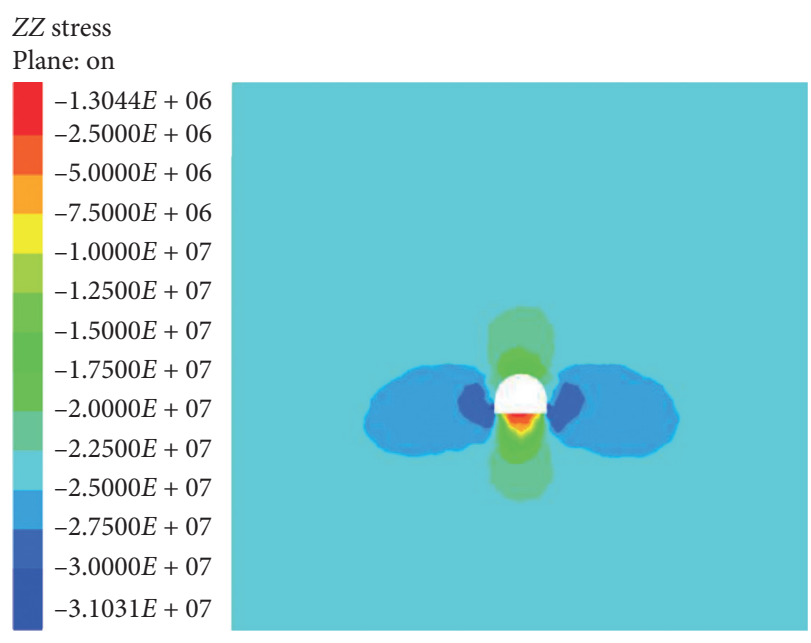

(a)

\section{$Z$-displacement}

Plane: on

$1.4540 E-01$
$1.3000 E-01$
$1.0000 E-01$
$9.0000 E-02$
$7.0000 E-02$
$5.0000 E-02$
$3.0000 E-02$
$1.0000 E-02$
$-1.0000 E-02$
$-3.0000 E-02$
$-5.0000 E-02$
$-5.3264 E-02$

$-5.3264 E-02$
YY stress

Plane: on

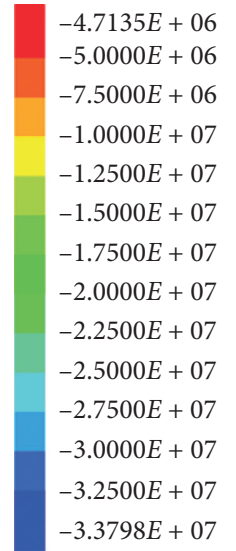

$-3.3798 E+07$

$Y$-displacement Plane: on

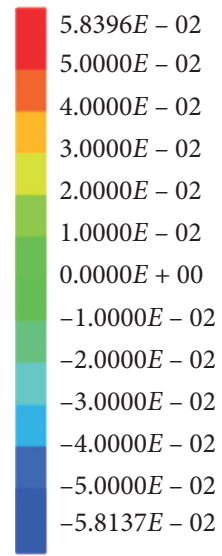

$-5.8137 E-02$

(c)

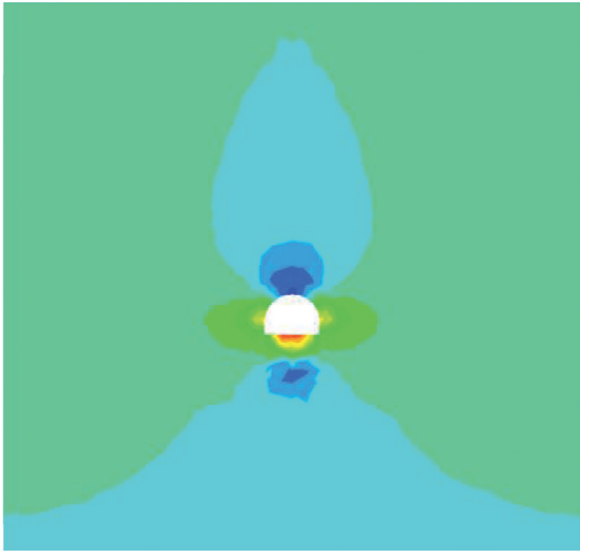

(b)

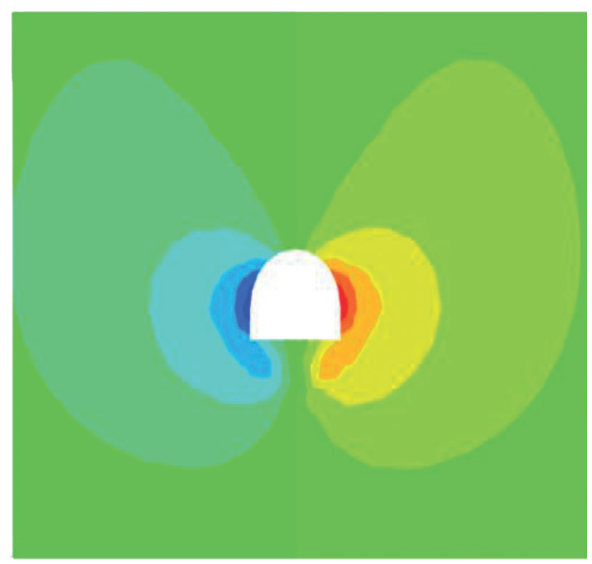

(d)

Block

Plane: on

Color by: state

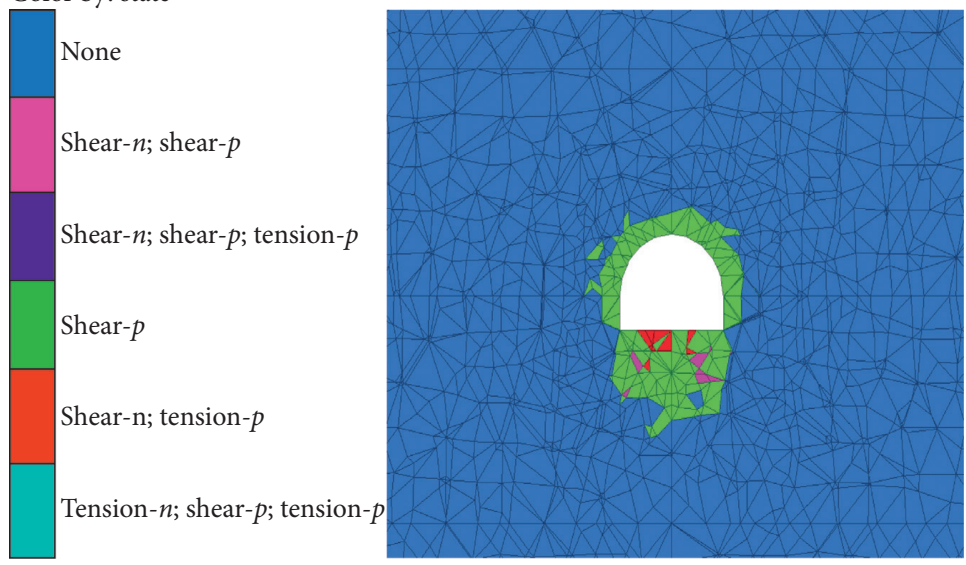

(e)

FiguRE 16: Numerical simulation results of constant-resistance rigid and flexible coupling support: (a) horizontal stress, (b) vertical stress (unit: Pa); (c) Z-displacement, (d) Y-displacement (unit: m), and (e) plastic zone. 


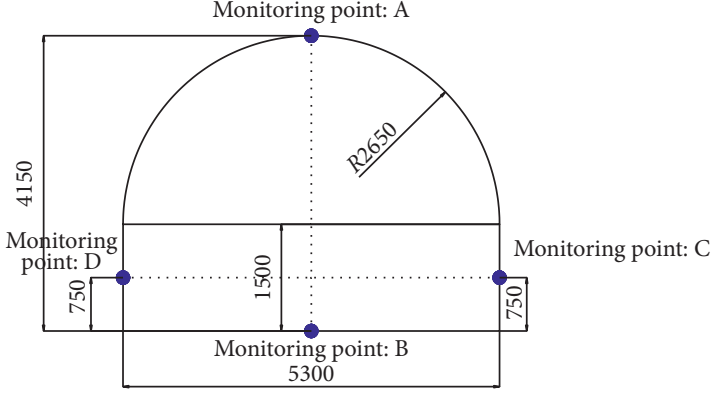

(a)

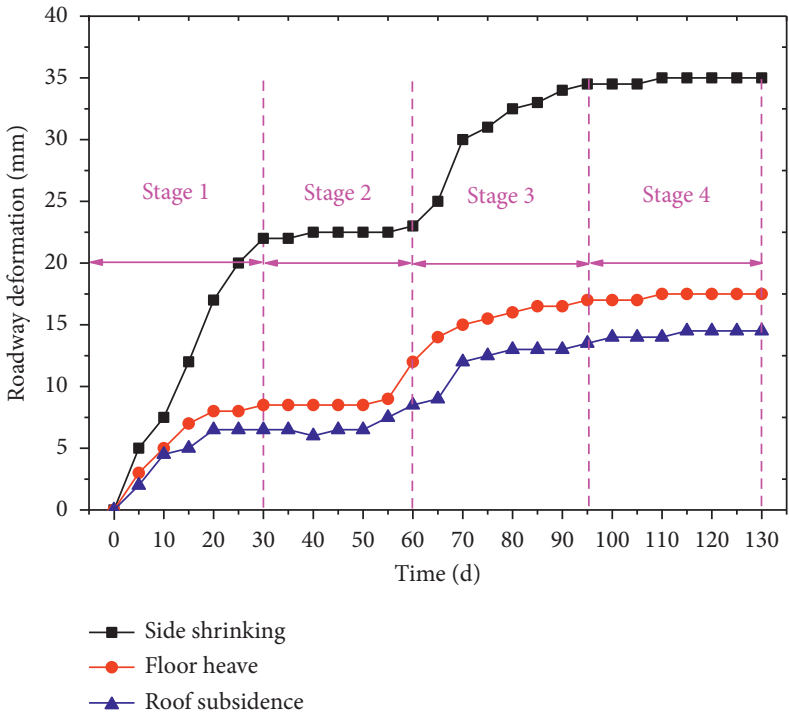

(b)

FIGURE 17: Monitoring curve of surrounding rock deformation of the entrance roadway: (a) distribution of the monitoring points; (b) curves of convergent deformation.

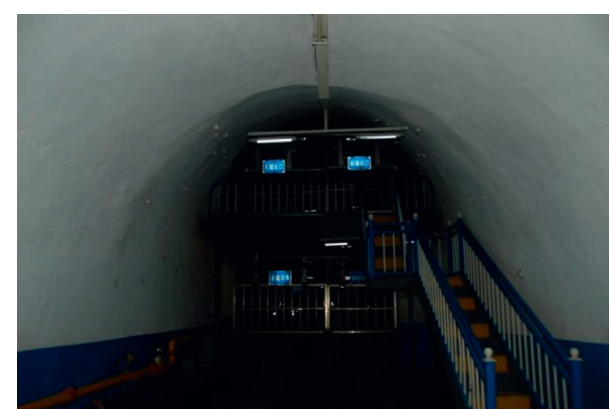

Figure 18: Application effect.

change is slower than the first stage. The deformation of surrounding rock is mainly affected by the excavation of the other side of the roadway.

During the fourth stage, the change of the displacement rate was small; 35 days later, after the new reinforcement scheme has been implemented, the deformation reaches the stable state. The monitoring results show that, by applying the new support scheme, the deformation of the surrounding rock is effectively controlled. The field application effect is shown in Figure 18.

\section{Conclusion}

(1) The -890 entrance to the Daqiang Coal Mine is a typical soft rock roadway. The failure characteristics of the surrounding rock are asymmetrical and show large deformation and duration. Numerical simulation shows that the bearing capacity of the shallow surrounding rocks under the original support system is poor, and the plastic zone is widely distributed, especially, where a large number of tensile shear units exist in the bottom strata, which aggravate the damage of the surrounding rocks.

(2) Based on the results of field investigation, laboratory tests, and theoretical analysis, the type of engineering soft rock is the HJS composite soft rock. Its deformation mechanism is type $\mathrm{I}_{\mathrm{AB}} \mathrm{II}_{\mathrm{AB}} \mathrm{III}_{\mathrm{ABC}}$. Based on this, the countermeasures for the stable transformation of soft rock roadway are proposed. Firstly, type $\mathrm{I}_{\mathrm{AB}} \mathrm{II}_{\mathrm{AB}} \mathrm{III}_{\mathrm{ABC}}$ is converted to type $\mathrm{II}_{\mathrm{AB}} \mathrm{III}_{\mathrm{ABC}}$ using the CRLD net spraying technique; secondly, type $\mathrm{II}_{\mathrm{AB}} \mathrm{III}_{\mathrm{ABC}}$ is transformed to type $\mathrm{II}_{\mathrm{AB}}$ using three-dimensional bolt optimization technology; finally, type $\mathrm{II}_{\mathrm{AB}}$ is transformed to type $\mathrm{II}_{\mathrm{B}}$ using the three-dimensional flexible truss support technology.

(3) To solve the large deformation problem of soft rock roadways, the CRRFC support technology is proposed. The CRRFC support system is composed of "CRLDAB + CRLDAC + flexible layer truss + concrete." This support technology controls the initial differential deformation of the surrounding rock through the combined support of CRLDAB and CRLDAC. Simultaneously, it fully releases the deformation energy accumulated in the surrounding rock by relying on its large deformation characteristics and improves the overall support effect of the surrounding rock by combining it with the high strength support effect of the flexible layer truss.

(4) Field investigation shows that, by applying the CRRFC support system, the large deformation of the surrounding rock in deep soft rock roadway is effectively controlled. The final deformation of the surrounding rock is controlled within $40 \mathrm{~mm}$ after 
long-term monitoring, which can guarantee the long-term stability of the soft rock roadway in the Daqiang Coal Mine so that it can provide reliable technical support for the safety of the deep soft coal mine and can be used as an example for similar conditions of a roadway.

\section{Data Availability}

The data used to support the findings of this study are included within the article.

\section{Conflicts of Interest}

The authors confirm that there are no known conflicts of interest associated with this publication and there has been no significant financial support for this work that could have influenced its outcome.

\section{Acknowledgments}

This work was supported by National Natural Science Foundation of China Youth Fund (Grants nos. 51904306 and 51874311), the National Key Research and Development Plan of China (Grant no. 2016YFC0600901), the State Key Laboratory of Open Funds (Grant no. SKLGDUEK1826), the Special Fund of Basic Research and Operating (Grant no. 2009QL03), and the Yueqi Outstanding Scholar Award Program of China University of Mining and Technology, Beijing.

\section{References}

[1] M. He, H. Xie, S. Peng et al., "Study on rock mechanics in deep mining engineering," Chinese Journal of Rock Mechanic and Engineering, vol. 24, no. 16, pp. 2803-2813, 2005, in Chinese.

[2] S. C. Li, Q. Wang, H. T. Wang et al., "Model test study on surrounding rock deformation and failure mechanisms of deep roadways with thick top coal," Tunnelling and Underground Space Technology, vol. 47, pp. 52-63, 2015.

[3] Z. Ma, Y. Jiang, W. Du, Y. Zuo, and D. Kong, "Fracture evolution law and control technology of roadways with extra thick soft roof," Engineering Failure Analysis, vol. 84, pp. 331-345, 2018.

[4] B. Wang, T. Li, C. He, and Y. Zhou, "Characteristics, causes and control measures of disasters for the soft-rock tunnels in the Wenchuan seismic regions," Journal of Geophysics and Engineering, vol. 13, no. 4, pp. 470-480, 2016.

[5] W. Zhang, Z. He, D. Zhang, D. Qi, and W. Zhang, "Surrounding rock deformation control of asymmetrical roadway in deep three-soft coal seam: a case study," Journal of Geophysics and Engineering, vol. 15, no. 5, pp. 1917-1928, 2018.

[6] S. Chen, A. Wu, Y. Wang, X. Chen, R. Yan, and H. Ma, "Study on repair control technology of soft surrounding rock roadway and its application," Engineering Failure Analysis, vol. 92, pp. 443-455, 2018.

[7] Y. Zhang, S. Fuxin, X. Sun et al., "Stress and deformation law of surrounding rock in the second reuse of roadway formed by roof cutting in the "three soft" coal seam," Journal of China University of Mining \& Technology, vol. 49, no. 2, pp. 247-254, 2020.
[8] Q. Wang, B. Jiang, R. Pan et al., "Failure mechanism of surrounding rock with high stress and confined concrete support system," International Journal of Rock Mechanics and Mining Sciences, vol. 102, pp. 89-100, 2017.

[9] Q. Wang, R. Pan, B. Jiang et al., "Study on failure mechanism of roadway with soft rock in deep coal mine and confined concrete support system," Engineering Failure Analysis, vol. 81, pp. 155-177, 2017.

[10] X. Sun, M. He, and X. Yang, "Research on nonlinear mechanics design method of bolt-net-anchor coupling support for deep soft rock tunnel," Rock and Soil Mechanics, vol. 27, no. 7, pp. 1061-1065, 2006.

[11] S.-Q. Yang, M. Chen, H.-W. Jing, K.-F. Chen, and B. Meng, "A case study on large deformation failure mechanism of deep soft rock roadway in Xin'an coal mine, China," Engineering Geology, vol. 217, pp. 89-101, 2017.

[12] L. P. Srivastava and M. Singh, "Empirical estimation of strength of jointed rocks traversed by rock bolts based on experimental observation," Engineering Geology, vol. 197, pp. 103-111, 2015.

[13] L. Yuan, J. Xue, Q. Liu et al., "Surrounding rock stability control theory and support technique in deep rock roadway for coal mine," Journal of China Coal Society, vol. 36, no. 4, pp. 535-543, 2011, in Chinese.

[14] X.-M. Sun, Y. Zhang, D. Wang, J. Yang, H.-C. Xu, and M.-C. He, "Mechanical properties and supporting effect of CRLD bolts under static pull test conditions," International Journal of Minerals, Metallurgy, and Materials, vol. 24, no. 1, pp. 1-9, 2017.

[15] S. Niu, H. Jing, Z. Zhang, and S. Yang, "Study on control technology of surrounding rocks in deep soft roadway and its application," Journal of China Coal Society, vol. 36, no. 6, pp. 914-919, 2011, in Chinese.

[16] X. Sun and D. Wang, "Research on dynamic pressure instability mechanism and control countermeasure of deep pump room and chamber group in Nan Tun coal mine," Journal of China Coal Society, vol. 40, no. 10, pp. 2303-2312, 2015, in Chinese.

[17] H. P. Kang, J. Lin, and M. J. Fan, "Investigation on support pattern of a coal mine roadway within soft rocks-a case study," International Journal of Coal Geology, vol. 140, pp. 31-40, 2015.

[18] M. He, H. Jing, and X. Sun, "Concept and classification of soft rocks," in Soft Rock Engineering Mechanics, 2nd, vol. 2, pp. 12-19, Science Press, Beijing, China, 2002.

[19] Q. Meng, L. Han, Y. Xiao, H. Li, S. Wen, and J. Zhang, "Numerical simulation study of the failure evolution process and failure mode of surrounding rock in deep soft rock roadways," International Journal of Mining Science and Technology, vol. 26, no. 2, pp. 209-221, 2016.

[20] M. He, Q. Gan, C. Cheng et al., "Deformation and damage mechanisms and coupling support design in deep coal roadway with compound roof," Chinese Journal of Rock Mechanics and Engineering, vol. 26, no. 5, pp. 987-993, 2007.

[21] Y. Zhang, X. Sun, Y. Zheng et al., "An anti-punching and energy-releasing coupling support technology in deep mining roadway and its application," Chinese Journal of Rock Mechanics and Engineering, vol. 38, no. 9, pp. 1860-1869, 2019, in Chinese. 